REVISTA IBEROAMERICANA. Vol. LXII, Núm. 174, Enero-Marzo 1996; 249-250

\title{
PAMELA BACARISSE
}

(1934-1996)

En pocos años la contribución de la Dra. Pamela Bacarisse al bienestar del Instituto Internacional de Literatura Iberoamericana y a la salud editorial de la Revista Iberoamericana fue nada menos que extraordinaria. Desde 1992 hasta su muerte el 18 de marzo de 1996, víctima de cáncer gástrico y pancreático, Pamela fue Secretaria-Tesorera del IILI, puesto para el que fuera elegida en el XXIX Congreso de Barcelona en 1992. Fue nombrada Presidente del XXX Congreso que ella organizó en Pittsburgh en 1994. Éste fue el segundo Congreso realizado en Pittsburgh durante los 33 años que ha cumplido esta universidad como sede del IILI, siendo el primero el que yo mismo organicé en 1979. No hay que señalar cuál de los dos resultó mejor, dado que Pamela Bacarisse fue la persona más organizada y eficiente que he conocido jamás.

Pero aun más fundamental para la supervivencia de la Revista Iberoamericana en los difíciles años transicionales que siguieron a la muerte en octubre de 1991 de quien fuera Director Ejecutivo del IILI durante 35 años, Alfredo Roggiano, fue el trabajo editorial verdaderamente heroico que hizo Pamela Bacarisse, el cual incluyó la lectura de docenas de artículos y la preparación de un número sencillo y cinco números dobles de la Revista Iberoamericana entre 1992 y 1994 . Sin su apoyo editorial (una labor sin recompensa pecunaria alguna), me hubiera sido imposible cumplir mis deberes heredados como Director Ejecutivo del IILI, sobre todo el de publicar con la puntualidad debida las entregas de la Revista. Al asumir la dirección del IILI y la Revista, fui a la vez Chair del departamento, pero contaba con la ayuda de Pamela Bacarisse. Por su parte, como prueba de su capacidad, hizo la mayor parte de su trabajo editorial siendo a la vez Chair del departamento entre 1992 y 1994.

Pamela Bacarisse fue profesora de literatura española, iberoamericana y portuguesa durante 20 años en la Universidad de Aberdeen, Escocia, desde 1969 a 1989. Se integró al profesorado del Departamento de Español inmediatamente después de terminar la licencia con First-Class Honours en español y portugués en la Universidad de Gales, Cardiff. Recibió la permanencia en 1973, y se doctoró en Aberdeen en 1976. Durante esos 20 años viajaba a Aberdeen las ciento ochenta millas de ida y vuelta desde su casa en St. Andrews, Escocia, en dónde vivía con su primer marido, Salvador Bacarisse, profesor numerario en el Departamento de Español en la Universidad de St. Andrews, y sus dos hijos, Claire y Benjamin. 
Como consecuencia de su divorcio en 1986 y las dificultades económicas de las universidades británicas bajo el gobierno de Margaret Thatcher, a los 55 años de edad se decidió a emprender una nueva carrera en otro país, otro continente y otro hemisferio. Se integró al Departamento de Lenguas y Literaturas Hispánicas de la Universidad de Pittsburgh como catedrática visitante en 1989. En 1991 recibió la permanencia y en 1992 fue elegida por el profesorado unánimemente Chair del departamento. Dejó ese puesto en 1994 para dedicarse más a la investigación literaria.

Autora en la última década de tres libros de crítica literaria y editora de otros tres, publicó asimismo numerosos artículos, reseñas y ponencias. Siempre valorizaba sobre todo sus dos estudios sobre la novelística de Manuel Puig, con quien mantuvo una gran amistad hasta la muerte repentina del escritor en 1990. Pamela le dedicó a Puig el Simposio sobre el sexo y la sexualidad en las letras y cine hispánicos, el cual fue organizado por Pamela en Pittsburgh en abril de 1991, y en el que Puig iba a ser convidado de honor.

Su aporte final a la crítica literaria iberoamericana es la edición en dos volúmenes de Tradición y actualidad de la literatura iberoamericana: Actas del XXX Congreso del Instituto Internacional de Literatura Iberoamericana (Pittsburgh: IILI, 1995), aparecida unos pocos meses antes de su muerte. Aunque fue abreviada brutalmente su vida, dejó un rico legado de scholarship y la viva memoria de una persona abierta totalmente a la vida y a sus prójimos de toda clase y raza.

Echamos de menos profundamente a Pamela Bacarisse no sólo yo, su marido y colega, sino también sus muchos amigos, colegas y estudiantes en Europa y en las dos Américas.

\author{
Keith McDuffie \\ Director Ejecutivo \\ INSTITUTO INTERNACIONAL DE \\ LITERATURA IBEROAMERICANA
}

